\title{
The Influence of the Vibroacoustic Environment Conditions on Functional Stability of Drivers
}

\begin{abstract}
Z. DAMIJAN*
Department of Mechanics and Vibroacoustics, Faculty of Mechanical Engineering and Robotics

AGH - University of Science and Technology, al. Mickiewicza 30, 30-059 Kraków, Poland

Despite new technological solutions and attempts to improve the working conditions during the operation of vehicles, city bus drivers are still exposed to negative impacts of noise and vibrations. This research project was undertaken in response to the lack of holistic analyses of the environmental factors that might impact on the city bus drivers at work. No extensive major research was done to investigate the influence of the conditions at work on functional stability of bus drivers and basic physiological parameters of the human body (systolic and diastolic pressure, pulse rate, temperature in the ear channel, loading of postural muscles, blood circulation determined with the use of a thermovision camera, fatty tissue content, body mass and physical condition (squeezing and pressing exercises). the main purpose of this research program was to show the impacts that the conditions at work might have on bus drivers or to demonstrate that these impacts do no exist.
\end{abstract}

PACS numbers: 89.40.--a, 43.80.--n, 43.80.-p, 87.50.Y-

\section{Introduction}

Drivers appear to be the weakest link in the chain of traffic elements since their health problems might lead to collisions or accidents. That is why this occupation requires good physical and psychical conditions, so that the work should be done in manner ensuring the public safety. Because of these high requirements, the job of a bus driver is treated as a special category. Candidates have to be able to quickly respond to complex stimuli, must have an excellent visual and motional coordination, must be able to concentrate and divide their attention, they have to be fit and emotionally stable and to see and hear well. There are many factors in their work environment that negatively impact on the drivers' health and physical and psychical condition, for example on their functional stability $[1,2]$.

Effective driving of a city bus requires the driver's full abilities, knowledge, skills, attitudes and emotions. Driver's performance involves three aspects:

- physical condition (determined in the medical examination),

- psychical condition (determined in psychological aptitude tests for candidates),

— skills, abilities and attitudes of a driver.

Physical condition can be broadly understood as the bodily fitness determined by the structural and functional levels of the body systems. Psychical condition is a general term and means the adequate performance of psychical processes: mental processes, memory, attention which might be impacted by emotions and motivations. Literature on the subject often quotes the terms: postural balance and stability.

* corresponding author; e-mail: damijan@imir.agh.edu.pl
The balance condition is understood as vertical orientation of the body, which can be achieved by balancing of forces and moments of force acting upon the body and the bone system interacts with the muscular system (including the postural muscles).

Stability is broadly understood as the ability of an organism to regain the correct stance after a destabilising stimulus has been applied. Sensitivity to the magnitude of the stimuli is referred to as functional stability whereas the structural stability involves also the conditions that accompany the stimulants, for instants limitation of vision.

Several levels of the nervous system are responsible for stability of the vertical position in humans. Three basic inputs are involved: atrial, visual and proprioceptive as well as mechanoreceptors present in the skin. Signals from these inputs control the body posture and its orientation with respect to internal and external reference systems. External systems are formed based on the gravitation field and visual stimuli. Internal systems are generated in the central nervous system by polimodal representations, also referred to as body schema [4-7].

The typical upright position implicates the vertical arrangement of the body axis with respect to a small supporting surface. This orientation in the gravitation field and multi-segment body structure, its height and small surface of support cause instability of the standing body in static conditions. Ongoing regulation and adjustment through the balance control system in the human body ensures its stability. Balance control involves static and dynamic balancing of destabilising gravity and inertia forces (and their moments) and activation of appropriate groups of muscles $[8,9]$.

As people get older, the anatomy, biochemistry and physiology of the human body are beginning to change and these changes might negatively impact on body functions, sensitivity of the nervous systems tends to decrease while the inertia increases. The vision range and preci- 
sion, eye accommodation ability and depth vision are impaired and the ability to distinguish colours is hindered, too. As one gets older, psychical and physiological functions tend to deteriorate $[9,10]$.

\section{Methodology}

Participants were selected from the group of bus drivers from the Municipal Transport Company in Ty- chy. Tests were continued from 24 to 31 March 2008. All participants were assumed to be healthy. The eligibility criterion in the selection of participants was the medical condition of candidates, who were qualified for the program by the doctor. Having learnt about the experimental procedure, each bus driver gave his written consent to participate. The group of participants consisted of 14 bus drivers, all males, aged 24-49. The anthropometric data are summarised in Table I.

TABLE I

Anthropometric data for the test sample.

\begin{tabular}{l|c|c|c|c|c|c|c|c}
\hline \hline \multicolumn{1}{c|}{ Variable } & Mean & $\begin{array}{c}\text { Confidence } \\
-95 \%\end{array}$ & $\begin{array}{c}\text { Confidence } \\
+95 \%\end{array}$ & Median & Min. & Max. & $\begin{array}{c}\text { Standard } \\
\text { deviation }\end{array}$ & $\begin{array}{c}\text { Standard } \\
\text { error }\end{array}$ \\
\hline Height [cm] & 174.93 & 172.38 & 177.48 & 175.00 & 169.00 & 186.00 & 4.41 & 1.18 \\
Body mass [kg] & 85.32 & 77.99 & 92.65 & 82.68 & 64.77 & 109.43 & 12.69 & 3.39 \\
Age [years] & 41.64 & 37.88 & 45.41 & 42.50 & 24.00 & 49.00 & 6.52 & 1.74
\end{tabular}

TABLE II

Dependent variables and their definitions.

\begin{tabular}{l|l}
\hline \hline Dependent variable & Definition \\
\hline Area $\left[\mathrm{mm}^{2}\right]$ & $\begin{array}{l}\text { Area of feet impressions expressed as the sum of the areas of activated sensors, } \\
\text { rounded off to account for interpolation in the case of sensors located on the } \\
\text { boundary of feet impressions. }\end{array}$ \\
\hline Maximal pressure $[\mathrm{kPa}]$ & The highest pressure registered by a single sensor. \\
\hline Average pressure $[\mathrm{kPa}]$ & Average pressure computed for the sum of activated sensors. \\
\hline Path length $[\mathrm{mm}]$ & $\begin{array}{l}\text { Length of curve determined by shifting the COG projection during the postural } \\
\text { balance measurements. }\end{array}$ \\
\hline Velocity $[\mathrm{mm} / \mathrm{s}]$ & $\begin{array}{l}\text { The ratio of Path length (see above) to the time of measurement- the average ratio } \\
\text { of deflections from the } X \text { or } Y \text { axis). }\end{array}$ \\
\hline Length to area ratio $[1 / \mathrm{mm}]$ & $\begin{array}{l}\text { Ratio of Path length to the area of an ellipse bounded on an oscillogram determined } \\
\text { on the axes showing maximal sway in the } X \text {-plane (side-to-side) and } Y \text {-plane } \\
\text { (front-back). }\end{array}$ \\
\hline $\begin{array}{l}\text { RMS velocity }[\mathrm{mm} / \mathrm{s}] \\
\text { Root mean square velocity }\end{array}$ & $\begin{array}{l}\text { Geometric sum of the rates of deflections from the } X \text {-axis (side-to-side) and } Y \text {-axis } \\
\text { (front-back) }\end{array}$ \\
\hline Average deflection $Y[\mathrm{~mm}]$ & Averaged sum of sways in the $Y$-axis (front-back). \\
\hline Average sway rate $Y[\mathrm{~mm} / \mathrm{s}]$ & Averaged sum of quotients of front-back sways $(Y$-axis) and the sway times. \\
\hline Average deflection $X[\mathrm{~mm}]$ & Averaged sum of sways in the $X$-axis (side-to-side). \\
\hline Average sway rate $X[\mathrm{~mm} / \mathrm{s}]$ & Averaged sum of quotients of side-to-side sways $(X$-axis) and the sway times.
\end{tabular}

Postural balance tests were performed with the use of the Win-pod platform (Figs. 1 and 2) manufactured by Medicapteurs company (France). The platform was connected to the PC via a USB port. The platform operation program version 3.1, enabling real-time analyses, was implemented in Windows. The platform consists of a board $(40 \times 40 \mathrm{~cm})$ with mounted tensometric sensors to register the pressure forces and moments of force exerted by the patient's feet on the board. Sensors register displacements of the patient's COG (centre of gravity) in the plane determined by the platform. Displacement signals, converted into digital form, are recorded in the computer system and displayed in real time. The computer is used to derive the COP (centre of pressure) of the patient's feet which is interpreted as the projection of COG onto the support plane in static conditions. Obtaining graphs of COP deflections is referred to as statokinesiography, posturography or stabilography.

Experiments were performed in accordance with the approved algorithm, shown in Fig. 3. Stability tests were performed in the upright position, eyes open. 
Descriptive statistics and test of significance of differences.

TABLE III

\begin{tabular}{|c|c|c|c|c|c|c|c|c|c|}
\hline Variable & $\begin{array}{l}\text { Mean } \\
\text { value }\end{array}$ & $\begin{array}{c}\text { Confidence } \\
-95 \%\end{array}$ & $\begin{array}{c}\text { Confidence } \\
+95 \%\end{array}$ & Min. & Max. & $\begin{array}{l}\text { Standard } \\
\text { deviation }\end{array}$ & $\begin{array}{l}\text { Standard } \\
\text { error }\end{array}$ & $\begin{array}{l}\mathrm{P} \text { for } \\
\text { tests }\end{array}$ & $\begin{array}{l}\text { Fraction of } \\
\text { change [\%] }\end{array}$ \\
\hline Length OP [mm] & 154.78 & 132.08 & 177.48 & 90.95 & 229.22 & 39.32 & 10.51 & \multirow{2}{*}{$0.01^{*}$} & \multirow{2}{*}{$\mathrm{i}-71.4$} \\
\hline Length OK [mm] & 165.27 & 139.80 & 190.74 & 94.48 & 234.75 & 44.11 & 11.79 & & \\
\hline Area OP $\left[\mathrm{mm}^{2}\right]$ & 73.80 & 53.83 & 93.77 & 32.83 & 145.00 & 34,59 & 9.24 & \multirow{2}{*}{$0.14^{* *}$} & \multirow{2}{*}{$\mathrm{i}-78.6$} \\
\hline Area OK $\left[\mathrm{mm}^{2}\right]$ & 77.61 & 64.24 & 90.97 & 50.00 & 121.33 & 23.14 & 6.19 & & \\
\hline Length/Area OP $[1 / \mathrm{mm}]$ & 2.33 & 1.92 & 2.74 & 1.18 & 3.74 & 0.71 & 0.19 & \multirow{2}{*}{$0.11^{* *}$} & \multirow{2}{*}{$\mathrm{d}-64.3$} \\
\hline Length/Area OK $[1 / \mathrm{mm}]$ & 2.19 & 1.90 & 2.48 & 1.67 & 3.43 & 0.50 & 0.13 & & \\
\hline Average velocity $\mathrm{Q}$ OP $[\mathrm{mm} / \mathrm{s}]$ & 4.70 & 4.03 & 5.36 & 2.98 & 6.95 & 1.15 & 0.31 & \multirow{2}{*}{$0.004^{*}$} & \multirow{2}{*}{$\mathrm{i}-71.4$} \\
\hline Average velocity $\mathrm{Q}$ OK $[\mathrm{mm} / \mathrm{s}]$ & 5.01 & 4.27 & 5.75 & 2.98 & 7.03 & 1.27 & 0.34 & & \\
\hline Velocity $X$ OP $[\mathrm{mm} / \mathrm{s}]$ & 2.96 & 2.45 & 3.48 & 1.73 & 4.68 & 0.89 & 0.24 & \multirow{2}{*}{$0.17^{*}$} & \multirow{2}{*}{$\mathrm{i}-64.3$} \\
\hline Velocity $X$ OK $[\mathrm{mm} / \mathrm{s}]$ & 3.13 & 2.56 & 3.69 & 1.67 & 4.63 & 0.98 & 0.26 & & \\
\hline Velocity $Y$ OP $[\mathrm{mm} / \mathrm{s}]$ & 3.58 & 3.08 & 4.08 & 2.13 & 5.12 & 0.87 & 0.23 & \multirow{2}{*}{$0.001^{*}$} & \multirow{2}{*}{$\mathrm{i}-78.6$} \\
\hline Velocity $Y$ OK $[\mathrm{mm} / \mathrm{s}]$ & 3.86 & 3.33 & 4.39 & 2.38 & 5.38 & 0.92 & 0.25 & & \\
\hline$X$ Average OP $[\mathrm{mm}]$ & 1.95 & 1.73 & 2.18 & 1.17 & 2.63 & 0.40 & 0.11 & \multirow[t]{2}{*}{$0.026^{*}$} & \multirow[t]{2}{*}{$\mathrm{i}-71.4$} \\
\hline$X$ Average OK. $[\mathrm{mm}]$ & 2.23 & 1.93 & 2.53 & 1.48 & 3.48 & 0.52 & 0.14 & & \\
\hline$Y$ Average OP $[\mathrm{mm}]$ & 2.95 & 2.29 & 3.61 & 1.85 & 5.08 & 1.14 & 0.30 & \multirow{2}{*}{$0.98^{* *}$} & \multirow{2}{*}{-} \\
\hline$Y$ Average OK $[\mathrm{mm}]$ & 2.89 & 2.56 & 3.22 & 2.00 & 3.95 & 0.57 & 0.15 & & \\
\hline Width bb OP [mm] & 9.36 & 8.24 & 10.47 & 6.18 & 13.08 & 1.93 & 0.51 & \multirow{2}{*}{$0.01^{*}$} & \multirow{2}{*}{$\mathrm{i}-78.6$} \\
\hline Width bb OK [mm] & 10.39 & 8.95 & 11.83 & 6.47 & 15.42 & 2.49 & 0.67 & & \\
\hline Average deflection bb OP [mm] & 1.94 & 1.71 & 2.17 & 1.17 & 2.63 & 0.40 & 0.11 & \multirow{2}{*}{$0.016^{*}$} & \multirow{2}{*}{$\mathrm{i}-71.4$} \\
\hline Average deflection bb OK $[\mathrm{mm}]$ & 2.23 & 1.93 & 2.53 & 1.48 & 3.48 & 0.52 & 0.14 & & \\
\hline Width pt OP $[\mathrm{mm}]$ & 13.59 & 10.89 & 16.29 & 8.68 & 21.95 & 4.68 & 1.25 & \multirow{2}{*}{$0.975^{* *}$} & \multirow{2}{*}{-} \\
\hline Width pt OK [cm] & 13.42 & 11.98 & 14.86 & 10.30 & 18.27 & 2.49 & 0.67 & & \\
\hline Average deflection pt OP $[\mathrm{mm}]$ & 2.95 & 2.29 & 3.61 & 1.85 & 5.08 & 1.14 & 0.30 & \multirow{2}{*}{$0.975^{* *}$} & \multirow{2}{*}{-} \\
\hline Average deflection pt OK [mm] & 2.89 & 2.56 & 3.22 & 2.00 & 3.95 & 0.57 & 0.15 & & \\
\hline
\end{tabular}

Each measurement lasted about $60 \mathrm{~s}$. Before each test, the procedure was explained to the participants to make it wholly understandable. The participant would step on the platform with bare feet. When commanded by the test supervisor, the participant would step on the platform, assume the upright position and remain immobile, standing freely for $30 \mathrm{~s}$. 17 decision variables and their definitions are compiled in Table II.

For clarity, the test situations are designed as follows:

— test before work- eyes open "Variable OP",

— test after work- eyes open "Variable OK".

where $O$ - denotes the test situation - eyes open, $P$ - initial measurement, was taken before work and $K$ final measurement, was taken after work.

Primary data are treated statistically by numerical methods in accordance with the statistical inference algorithm. Analysed parameters include the primary data scatter, to eliminate measurement errors and errors involved in writing the problem in the matrix format.

Having eliminated the errors in the result matrix, the descriptive statistics were obtained for all variables (mean value, median, maximum, minimum, standard deviation, standard error, confidence -95\%, 95\%). The Lilieforse and Shapiro-Wilk tests were applied to test the

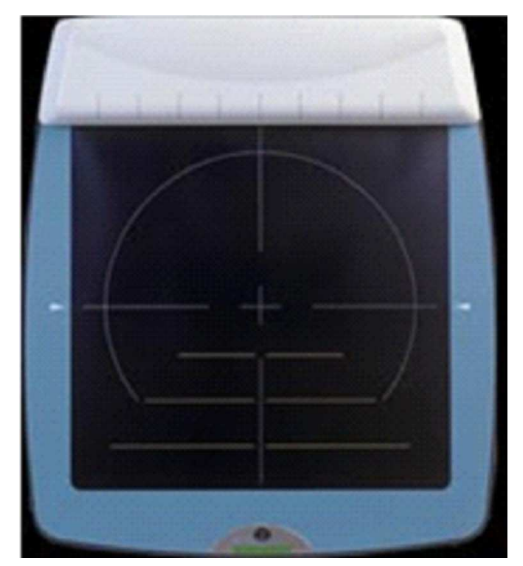

Fig. 1. Win-pod platform.

normality of distributions. In accordance with the approved confidence test selection algorithm, the difference between the confidence levels for normally distributed dependent variables was evaluated using the $T$ test (designated as*), whereas the nonparametric Wilcoxon test was used $\left({ }^{* *}\right)$ to handle variables that do not display normal distribution (Table III; $i$ - increase, $d$ - decrease). 


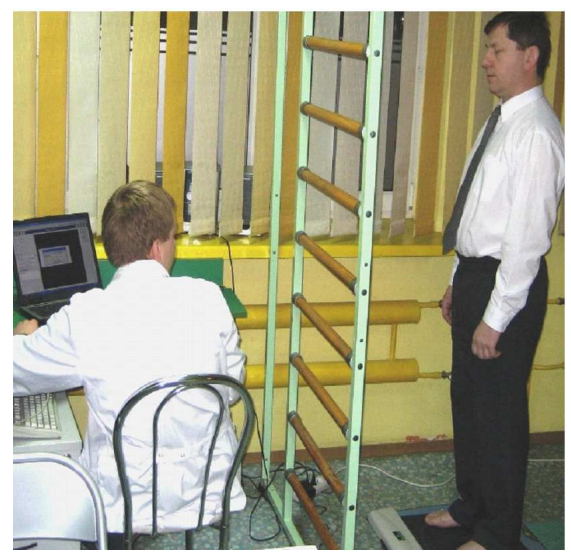

Fig. 2. Experimental set-up.

\section{Specific conclusions}

Experimental data supported by statistical analyses reveal that the working conditions of bus drivers lead statistically significant increase in the value of several posturographic parameters:

— Length [mm] from $154.78 \pm 39.32$ to $165.27 \pm 44.11$; $71.4 \%$ of the sample displaying increase,

- Average velocity $Q[\mathrm{~mm} / \mathrm{s}]$ from $4.40 \pm 1.15$ to $5.01 \pm$ $1.27 ; 71.4 \%$ of the sample displaying increase,

- Velocity $Y[\mathrm{~mm} / \mathrm{s}]$ from $3.58 \pm 0.87$ to $3.86 \pm 0.92$; $78.6 \%$ of the sample displaying increase,

- Average $X[\mathrm{~mm}]$ from $1.95 \pm 0.40$ to $2.23 \pm 0.52$; $71.4 \%$ of the sample displaying increase,

— Width $b b[\mathrm{~mm}]$ from $9.36 \pm 01.93$ to $10.39 \pm 2.49$; $78.6 \%$ of the sample displaying increase,

- Average deflection $b b[\mathrm{~mm}]$ from $1.94 \pm 0.41$ to $2.23 \pm$ $0.52 ; 71.4 \%$ of the sample displaying increase.

\section{General conclusions}

Working conditions for city bus drivers lead to deterioration of functional stability of their posture. Further systematic research is still merited to fully investigate this issue.

This study is supported through the author's research grant no 10.10.130.631 and through the statutory research funds as a part of the project no 11.11.130.119. Authors express their gratitude to Ms Anna Krzymuska, a representative of Medicapteurs company in Poland for rendering available the Win-pod platform.

\section{References}

[1] J. Bak, News bulletin from the VI Conference of the Safety in the road traffic of motor vehicles of the army, Krosno Odrzańskie 2007, (in Polish).

[2] D. Starkowski, K. Bieńczak, W. Zwierzycki, Operating environment of the driver, Logistics, Vol. III, 2005, (in Polish).

[3] J.W. Błaszczyk, in: Biomechanika Kliniczna, PZWL, 2004, p. 192.

[4] J.W Błaszczyk, P.D. Hansen, D.L. Lowe, Acta Neurobiol. Exp. 53, 155 (1993).

[5] J.W Błaszczyk, A. Piórko, D.H. Lowe, P.D. Hansen, Biocyber. Biomed. Engin 14, 97 (1994).

[6] J. Olton, Posturograf, Pro-Med., 2004, (in Polish).

[7] J.W. Błaszczyk, W. Klonowski, Acta Neurobiol. Exp. 61, 105 (2001).

[8] J.W. Błaszczyk, Biomechanika Kliniczna, PZWL, Warszawa 2004, p. 192.

[9] J.W. Błaszczyk, L. Czerwosz, Postural stability in the ageing process - demonstrative work, Vol. 13, 2006, (in Polish).

[10] G. Dahlke, in: Conference materials — road safety education and diagnostics steering vehicles, Warszawa 2007, (in Polish). 